\title{
A Case Study of the Role of ICT in a Grade 6 Classroom
}

\author{
Audrey Cooke, Vaille Dawson \\ Curtin University, Australia
}

\begin{abstract}
ICT use in classrooms has been under investigation since it first began being used in education, often with mixed results on the impact and worthiness of ICT. The research in this paper examined the self-reported confidence and competence in ICT of a Grade 6 teacher and students at a Western Australian Catholic primary school as well as the use of ICT in the classroom. The study incorporated interviews, questionnaires, and observation of a literacy lesson where ICT was used by the teacher and students. Findings indicate that the teacher and students rated themselves as both competent and confident in ICT and considered ICT as an important part of the lesson and of the teacher's role. The findings support research on the impact of the teacher on the use of ICT in the classroom, both in terms of their use of ICT and the use of ICT by their students.
\end{abstract}

\section{Introduction}

Information and communication technologies (ICT) have been available to education since the 1980s, resulting in the question of how ICT has been and is being used in schools. The impact of ICT on our world is mimicked in education, but the effect is on more than just the social and cultural aspects as ICT also impact on pedagogy and teacher skills [1]. This creates the opportunity to increase how rewarding and meaningful both teaching and learning can be [1]. Even though there are many with an interest in the use of ICT in education, the responsibility for implementing technology within the classroom will more than likely fall to the teacher and, potentially, their students [2]. As a result, how competent and confident the teachers consider themselves in ICT could contribute to their use of ICT in the classroom. Furthermore, the teacher's beliefs regarding how ICT should be used and the part ICT plays in the role of the teacher are also potential factors that may contribute to the use of ICT by that teacher. Added to the teacher's beliefs is the possibility of their students either knowing more or believing they know more regarding ICT.

When investigating the use of ICT in education, there are two types of studies regarding ICT [4], those prescribing its use and those describing its use. This study is firmly placed within the second category as it is inquiring about what is happening, not how it should happen.

\section{Background}

\subsection{Use of ICT in primary classrooms}

For the purpose of this study, ICT is defined as desktop, laptop, and handheld computers that run software and can enable access to the Internet, along with software and using the Internet itself. Thus, this definition includes hardware (as long as it could access the internet via software), software, and the internet (note that the research was conducted before May 2010 and iPads and androids were not available).

ICT has been lauded as providing new ways of learning for students. Using technology appropriately enables teachers to enrich student learning as well as better cater for differences in how their students learn [4]. Additionally, it can greatly assist teachers in providing different learning experiences without adding to their work load [4]. In terms of ICT enabling meaningful contexts, access to ICT is important but the context in which learning occurs also needs to be meaningful for the students [5].

However, the potential changes that ICT may bring are not isolated to its presence in the classroom nor limited to the impact on student learning. The use of ICT can also impact on the teacher. The changes in education as a result of ICT reflect not only the needs of a society with new technology, but also in how teachers teach [6]. Teachers have to be responsive to the change and even propagate the changes involved [6]. However, to do this, teachers need to be able to use ICT effectively and to use it appropriately in the classroom to ensure how it is used helps student learning rather than hindering student learning [6]. This moves the role of the teacher from just using ICT to being able to use it in a pedagogically sound manner. 


\subsection{ICT and the role of the teacher}

ICT does not sit alone or separate from the role of the teacher. Teachers need to consider ICT in conjunction with their beliefs about and attitudes towards teaching, as ICT has the capacity to change what has previously been perceived as the role of the teacher and the student [7]. The potential of ICT to impact on teaching creates the opportunity for teachers to make changes. These changes involve learning how to use new ICT and changing how they teach to enable the incorporation of ICT into their teaching [7]. Teachers do not always make these changes, as even though teachers can see the potential of ICT in the classroom, they may focus on using skill-based applications as these can slide into their existing view of teaching and learning [8].

Using ICT in place of a different non-ICT resource reflects the lowest level of support that ICT can provide to pedagogy [9], where a non-technical aspect of the teaching and learning is replaced without changes to the lesson delivery or student learning. The next level is where ICT is used to amplify an aspect of the lesson through the creation of a more efficient or more powerful aspect than was possible via the nontechnical process or product it is replacing [9]. However, again, no change occurs in the lesson or learning. The third way to use ICT is to transform the lesson by changing how the lesson is conducted and the student learning that is involved [9]. This involves changes beyond the incorporation of ICT as a replacement resource.

\subsection{Differences in teacher and student ICT use}

Initial research into teacher and student use of ICT considered the impact of the different access each successive generation has had to ICT in their environment. The exposure of students to a plethora of ICT in their everyday environment raises may raise their expectation that their teachers will also be exposed to ICT in the same way [10]. This expectation of students has a mirror expectation from teachers, with the teachers believing that their students will know more about ICT as they are immersed in a technology-rich out-of-school environment [11]. However, it has the added dimension where teachers may feel intimidated by their perceived lower level of knowledge of ICT than of that of their students [11].

Teacher-perceived deficiencies in ICT knowledge and skills when compared to their students can escalate to concerns. There is the potential impact of situations where students know more than teachers about the ICT used in the classroom [4]. Teachers could feel threatened by the perceived disparity in ICT knowledge and skills, particularly in more open-ended learning environments that promote student-centred learning, as student ICT skills could advance beyond those of the teacher [4]. Nevertheless, one of the benefits of this situation is that the students' thinking and creativity may be undergoing greater development than expected [4].

\section{Research Method}

\subsection{Context}

This study was conducted in a Catholic Primary School. Initially, advice was sought from a colleague within the Catholic education sector to provide assistance in selecting schools that fitted the profile below and on determining a school that could be approached to participate in a pilot study. Schools in the study needed to have:

- A computer lab or set of laptops with a ratio of 1 computer to 2 students or less. The ratio was used as it has the potential to impact in terms of access to resources and how ICT is used;

- Year 5 and 6 teachers who use ICT, particularly computers, in their lessons.

- Primary grades only on campus (rather than a combined campus with both primary and secondary classes) to reduce the potential impact of catering to a cohort with possible access to resources aimed at older students.

- A metropolitan location to reduce the potential impact of rural location on the data as this could impact on access to the Internet.

- A school where only one class for each grade provided (referred to as "single stream”) was taught in the school. The aim of this criteria was to maintain coherence between school sizes as schools with two or more streams would have a larger cohort and this could affect infrastructure.

The class was a Grade 6 class and 20 students and their teacher participated. Grade six is the final year of education in Catholic primary schools. The My Schools website [12] provides information about schools in Australia and was used in conjunction with the information from the teacher interviews and follow up questions. The main information obtained from the My School Website [12] involved the school Index of Community Socio-Educational Advantage (ICSEA), which is also produced by the Australian Curriculum, Assessment and Reporting Authority (ACARA). The school ICSEA value placed it in the medium range, which coincides with the teacher's assessment of socio-economic status of the school as medium to high. 


\subsection{Aim of the research}

The aim of the research reported in this paper was to explore the self-reported confidence and competence in ICT of a Grade 6 class teacher and her students, the role that ICT plays in the classroom, and the part ICT was perceived to play in the role of the teacher. Specifically, the research questions were:

1. How can ICT be integrated into a Grade 6 classroom?

2. What are the teacher's and students' selfreported competence and confidence regarding ICT in a Grade 6 classroom?

\subsection{Research Design}

A case study method utilising three data sources interviews, observations, and questionnaires - was used to collect data, specifically both open-ended questions and Likert-style questions within the questionnaires for the students and teachers, pre- and post-observation interviews with the teacher, and classroom observations. Data from these were combined to create the case at the classroom level as this provided a physical and social context with which to delineate the case and to provide clear operational definitions [13]. The multiple data sources also provided triangulation [14], as the teacher's responses to the interview questions could be compared to what was observed in the lesson and both of these could be compared to the responses to questions on the questionnaires.

One 25 minute lesson using ICT was observed by the first author. Instances of student and teacher movements in the classroom, student and teacher vocalisations, student interactions with the ICT and other resources, student and teacher positioning, and lesson organisation were noted. The intent behind the observed behaviours was not obtained during the session as the observer did not interact with the teacher or students during the observation. However, as discussed later, at the pre-observation interview the teacher was asked about her intentions in using ICT in the lesson and at the post-observation interview, the teacher was asked about the behaviour exhibited by students during the observation and the use of ICT during the lesson.

The pre-observation interview incorporated questions regarding how the teacher planned to use ICT in the lesson, whether the teacher had a preferred way of using ICT in the classroom, and how ICT was used in the upcoming (observed) lesson as part of the learning outcomes for that lesson. The post-observation interview focused on questions regarding the teacher beliefs regarding the student behaviour and learning in the observed lesson. Specifically, these questions addressed whether the teacher thought the students stayed on-task during the lesson, whether there were other factors that affected the lesson, if the students behaved during the lesson as they usually do in a lesson with ICT, whether the students behaved in the same way as other students in a lesson with ICT, and what the teacher thought the students learned by using ICT in the observed lesson.

The teacher completed three questionnaires at the end of the post-observation interview. The first questionnaire was an open-ended questionnaire and contained questions regarding ICT skills and the role of the teacher. These questions concerned what the teacher saw as the ICT skills required by a primary school teacher, the importance they allocated to ICT in their role as a primary school teacher, and the other factors they believed should be considered together with ICT skills when teacher use of ICT was being evaluated or assessed. The second and third questionnaires were both Likert-style and presented a list of 12 ICT against which the teacher had to indicate how competent they believed they were in using that ICT and how confident they were in using that ICT. With regards to her competence, the teacher could rate herself from beginner (a rating of 1) to competent (a rating of 3) to expert (a rating of 5), with both 2 and 4 included. For confidence, the teacher could rate herself highly anxious (a rating of 1), confident (a rating of 3), and highly confident (a rating of 5), with additional ratings of 2 and 4 also available. At the end of the Likert-style confidence questionnaire, the teacher was asked an open-ended question regarding the factors that affect how confident she felt when using ICT in the classroom.

The students completed two Likert-style questionnaires with 12 specified ICT and these were completed at the conclusion of the observed lesson. The definition of ICT was provided at the top of each questionnaire and it was read aloud to students by the researcher. The researcher then explained to students how they would complete the questionnaire to show how competent they believed they were in using that ICT and how confident they were in using that ICT. With regards to their competence, the students could rate themselves from beginner (a rating of 1) to competent (a rating of 3 ) to expert (a rating of 5), with both 2 and 4 included. For confidence, the students could rate themselves highly anxious (a rating of 1), confident (a rating of 3), and highly confident (a rating of 5), with additional ratings of 2 and 4 also available. The researcher walked around the classroom answering student questions whilst the students completed the questionnaires. When they had finished, the students handed their completed questionnaires to the researcher.

The data collected from the students via the Likertstyle questionnaires was combined across students for 
each of the 12 ICT items for self-reported competence and self-reported confidence. Percentages were calculated to determine the proportion of students who reported being competent and higher or confident and higher for each of the 12 ICT items and these were compared to the responses from the teacher. The content in the teacher and student responses to openended questions on the questionnaires, and the frequency with which the teacher and students incorporated this content in their comments, was compared for each of the open-ended questions, to the results of the teacher interview, and to the result of the observation.

\section{Results}

\subsection{Classroom observation}

The lesson started 11:05 am. Laptops were set up prior to the start of the lesson, with one laptop allocated between pairs of students. There were a total of eight pairs, one three-some, and one individual. The teacher started the lesson with the students on the mat in front of the whiteboard to enable the use of the electronic whiteboard to demonstrate the program that would be used in the lesson. The students worked through an example and the teacher specified that students needed to provide feedback to their partner on their partner's work. The teacher then worked through the several steps to demonstrate what the students would do when they returned to their desks. A mix of the traditional whiteboard and the smart board was used, with the traditional board used for the list of spelling words (ie., static) and the electronic whiteboard was used to demonstrate the program (ie., dynamic). The teacher also used the zoom features on the electronic whiteboard, zooming in and out to show students relevant details. This section of the lesson was seven minutes long.

Students returned to their desks to work and the teacher walked around checking progress. When one laptop didn't work, the teacher asked the pair to swap to the classroom desktop. Apart from this instance, no student problems with the use of the laptops or computer program were observed.

The volume from the program generated one of two general statements to the class from the teacher. The first request involved asking the pair with the high volume to turn it down (though, as stated, this was a general request and not directed at the pair). The second instance involved the teacher reminding students to share the control of the mouse in the pairs. There were a further two interactions with specific pairs of students - one where the teacher stated both students should be able to see the laptop screen (as the laptop was turned slightly) and another where the teacher then a pair of students to lower the volume. At the beginning of the lesson, there was some interaction within pairs but very little between pairs. Towards the end of the session, there was much more interaction within pairs of students but not between pairs, though much of the interaction involved in the program.

After twelve minutes, the teacher requested the attention of the class and asked students to indicate if they enjoyed the game (all hands went up) and who had any spelling errors (a couple of hands went up). Two pairs of students were using their computer when the teacher was talking but the teacher addressed this. The laptops were packed away and the class returned to the mat. The teacher asked for a volunteer pair to use the electronic whiteboard to play the concentration game in front of the class. The teacher reminded the students to touch the screen one at a time. During the game, the class was watching and involved in the game. After four minutes, the teacher asked the students questions regarding the program and whether they would use the website in the holidays, and several students put up their hands up to indicate they would. After the question and answer session, the teacher finished by stating that it was work but also fun.

\subsection{Student questionnaires}

Twenty student responses to the first open-ended question regarding the type of ICT the student thought a primary school teacher needed to be able to use were collated. The most frequent response was laptops or notebooks (11), followed by the Internet (9), computer or desktops (9), electronic whiteboards (7), websites (4 mentioned either specific or generic websites), and email (3). The question regarding the importance of a primary school teacher being able to use ICT elicited 13 responses indicating it was important or very good. Ten responses to the question "What other things should be thought about when a teacher uses information and communication technology (ICT)?”, were "nothing" or "nothing really", two responses each concerned software, websites, or safety, and one response concerned information (there were two nonresponses from students to this question).

The importance ICT played in the lesson was addressed by an open-ended question and, of the 19 responses, 16 students wrote it was important whilst three wrote it was not important. Reasons given for why students considered it important included learning more or better (six responses), the need to use ICT to access the Internet (three responses), to find out information (two responses), for fun (one response), and computers and laptops are used in high school (one response). Of the three who stated it was not important, the reasons given were that it could have 
been learnt without ICT, learnt by themselves, and it was a waste of time.

The possibility of whether the lesson could be competed without ICT garnered eight responses for yes and eight responses for no, one response of "yes and no", and one response of "not sure". Students gave several reasons why the lesson could be completed without ICT- they could learn themselves or could already do the work (four responses), the activity could have been written (by hand) (two responses), and the teacher could teach without ICT (one response). Of the reasons given with the no responses, responses included that the Internet was needed (four responses), that ICT was needed to learn (two responses), and that ICT made it fun (one response).

The results for the Likert-style questionnaire for the students were administered as two sections, one on competence and one on confidence. A Cronbach's Alpha of 0.871 was calculated for the competence section and a Cronbach's Alpha of 0.865 was calculated for the confidence section.

The majority of students reported they were competent or expert in desktop or laptop (all students), followed by Internet browsers (95\% of students), document processors (95\% with one non-response), emailing (90\%), electronic whiteboard (89\% with one non-response), and presentation software (85\%). The lowest number of students reported themselves as competent or expert in for the ICT movie or DVD editing programs (56\% with nine non-responses).

The majority of students reported themselves as confident or highly confident in using the electronic whiteboard and Internet browsers (both 95\%, followed by desktop or laptops, presentation software, and email (all 90\% without non-responses). Least students reported themselves as confident or highly confident in using the photograph importing software (63\% with one non-response).

When self-reported competence ratings were averaged, the student average rating were highest for Internet browsers (average of 4.65), followed by email or messaging (4.25) and desktop or laptop computers (4.15). Internet browsers and desktop or laptop computers (both with an average of 4.45) had the highest average rating for self-reported confidence, followed by document processors (4.263) and email or messaging (4.20). The average ratings for selfreported confidence for using photograph importing software, Internet browsers, email or messaging were more than the average ratings for self-reported competence.

\subsection{Teacher questionnaires}

The teacher's response to the open-ended question regarding the ICT skills required of a teacher included general computer skills as well as skill with the resources available to them, with the electronic whiteboard and "various software packages" provided as examples. She saw ICT as very important in her role as a primary school teacher because she saw ICT as a part of the student's world and stated educators need to be "in touch" and relevant. The teacher indicated that ensuring the components worked effectively to minimise interruptions should be considered along with ICT skills when assessing a teacher's use of ICT.

The teacher rated herself the highest rating of expert in their use of overhead projectors (a rating of 5) and their lowest rating of competent in statistical or database software (a rating of 3), with all other items rated four (apart from palmtop computers, which was not rated at all, indicating that it was not used). The teacher's self-reported confidence was rated the same for all items (4) apart from palmtop computers and statistical or database software which both had a rating of 3.

\subsection{Teacher interviews}

The teacher's response to the first question in the pre-observation interview on how ICT would be used in the lesson outlined the use of the laptops by pairs of students to access a website for a spelling program. The teacher indicated this was her favoured option in her response to the question on the preferred way of using ICT in the classroom. Specifically, she stated her preference as two students per laptops, used in either the classroom or the laboratory, with the electronic whiteboard used for demonstrations (of the program or task). The teacher stated that ICT would be used as part of the learning outcomes by reinforcing how to spell the words correctly.

The post-observation interview focused on the observed lesson. The teacher was asked whether she though the students stayed on task during the lesson and she replied that she believed the students stayed on task during the lesson. She stated that the minimal distractions (some students had to leave during the lesson or arrive late due to Specialist music lessons) had little impact. Additionally, the teacher stated that the students behaved as they usually do in a lesson with ICT and that the behaviour was similar to other students they had worked with during a lesson with ICT. Finally, the teacher summarised the use of ICT in the lesson as benefiting the students as it reinforced the students' spelling (as the correct spelling of the word was needed when the spelling list was entered into the program), made the lesson different and exciting, and introduced the students to a program they could use on the holidays. 


\section{Discussion}

\subsection{How ICT was used}

As the teacher had stated in the pre-observation interview, the observations noted include that the electronic whiteboard was used to demonstrate the tasks requirements for the program and the students sat in mostly in pairs to share a laptop to access the program. This demonstrated cognisance between the teacher's beliefs about how ICT should be used and how the teacher actually used it in the observed lesson. This simpatico can be seen as essential for the successful use of ICT by teachers in the classroom [15]. In contrast, teachers may not use ICT to its potential as they restrict themselves using ICT in a way that is compatible with their pedagogy, rather than changing their pedagogy [8]. The teacher's preferred way of using ICT incorporated aspects that would not have been available without the ICT - even elements as basic as showing all of the students the screen that they would see or accessing the spelling program. However, half of the students responding to the question of whether the lesson could have been completed without ICT stated it could have and half stated it couldn't.

The teacher's use of ICT in the observed lesson also demonstrated a high degree of confluence with her stated aims for ICT that she provided in the postobservation interview - to reinforce spelling and to show students a program they could use in the holidays. This supports the position that it is appropriateness of use of the ICT that enhances learning for students [4] [16]. The observed lesson, where the electronic whiteboard and a spelling program (accessed from the Internet via (mostly) laptops) were used, enabled immediate feedback on the students' spelling. Additionally, six of the students incorporated aspects of learning in their response to why ICT was important in the lesson and six incorporated aspects using the ICT.

In both the responses to the pre-observation interview and the observed lesson, the teacher's use of the electronic whiteboard was linked to the later use of ICT in the lesson as it enabled a detailed description of how to access the program the students would use via the laptops. Even though electronic whiteboards are more prevalent in primary classrooms, findings regarding their effect on pedagogical practices are inconsistent [17]. However, two factors that impacted on the level of student interactivity in a lesson with an electronic whiteboard, both of which were driven by teacher choice, were the features that were used and how the teacher used these features [17]. The use of the electronic whiteboard enabled effective whole-class demonstrations of the programs to be used, as without the electronic whiteboard, a different strategy would be needed to explain the program. Additionally, the teacher called on students to respond either by providing answers to her questions or by controlling the electronic whiteboard, with both of these tasks involving the electronic whiteboard directly to maintain student interest. This reflected the teacher's statement in the post-observation interview regarding the use of ICT helping students learn in the lesson as it was "different and exciting".

When working with the ICT, the students stayed involved, whether they were using the laptop or sitting on the mat in front of the electronic whiteboard. There are two potential reasons for the level of engagement observed - the short sessions (seven minutes for the demonstration on the electronic whiteboard, twelve minutes on the laptops, six minutes playing the game on the electronic whiteboard and answering questions about the game) and the effect of keeping students motivated and interested [18], which also relates to the active engagement of students [16]. Two behaviours were observed where student actions had the potential to disengage the other students. These observed behaviours were related to the use of the ICT (ie., the volume of the sound effects and music) and how it impacted on surrounding students. The teacher addressed these behaviours via a general statement to the whole class in the first instance and a statement direct to the pair involved in the second instance.

Overall, the observed use of ICT in the classroom and the teacher's responses regarding how she uses ICT and why she uses ICT in that way, reflect the higher descriptions of ICT and pedagogy [9]. Efficiencies were created in two ways - through the use of the electronic whiteboard to show all students aspects of the task (which were quite detailed at times) and by the use of a spelling program that provided the students with their results, without the teacher marking the work as happens in traditional spelling lessons. An additional feature of the spelling program, the immediacy of the provision of spelling results, and the use of the features of the electronic whiteboard to zoom in to highlight important aspects of the task, enabled changes to how the lesson was conducted and the student learning.

\subsection{ICT and the role of the teacher}

As can be seen from the teacher's self-reported competence and self-reported confidence ratings for the electronic whiteboard (both rated 4 out of 5), the teacher rated herself more than competent and more than confident in her use of that ICT. The importance of teachers being able to use "various software 
packages" and the consideration of working components were provided by the teacher as factors that should be considered along with teacher ICT skills. Together, these results reflect the influence ICT has on the teacher's pedagogy [17]. Additionally, it feeds into the interaction between pedagogy and technology that can be more efficient and powerful or transforming [9].

In the post-observation interview, the teacher stated that her use of the spelling program was to reinforce the students' spelling, make the lesson exciting, and introduce the students to a program they could access out of school. They reflect two potential benefits of using a spelling program - immediate feedback and working with computers [18]. The teacher's response regarding making the lesson different and exciting reflected the capacity of ICT to motivate students in a task they may not enjoy (spelling) [18], and the teacher's statement regarding encouraging students to access the program out of school evidenced the motivational aspect of ICT. This also resonates with the belief that ICT should be used to help student learning and not hinder it [6].

The teacher also stated in the questionnaire that "ICT is part of the student's world, educators need to be 'in touch' and relevant". This statement is congruent with the proposal that the impact of ICT in the world should be reflected in education [1]. The environment in which the students find themselves needs to be brought into the classroom to provide context for the student learning as this can encourage students to view the task and learning as meaningful [5].

\subsection{Teacher and student comparison}

The teacher's responses to the Likert-style questionnaires on confidence were all confident to highly confident reflected her strongly affirmative response to the open-ended question on whether ICT is important in her role as a primary school teacher. Aligning the student responses with the teacher's responses, palmtop computers had the highest nonresponse rate (4 students did not rate this, which was the appropriate response if they did not use it). The same number of students did not respond to the question on competence with movie or DVD editing programs, and this ICT also rated the lowest responses of competence or highly competent from students. These responses would indicate that teacher confidence in using ICT resulted in students who used that ICT more [19].

Whereas the teacher's responses to the Likert-style questions were confident to highly confident and competent to expert with one item not reported on (palmtop computers), there were more instances where students reported lower ratings of confidence and competence, along with more items that had nonresponses (indicating the student did not use that ICT). However, research into whether there is a relationship between student perceived competence and actual competence needs to be investigated [20]. This aspect was beyond the scope of research.

\section{Conclusion}

The teacher's use of the ICT in ways that reflect her beliefs was consistent with existing descriptions of ICT adoption [15] [17]. The interaction between the teacher's pedagogy and the ICT, and the efficiencies created in the use of the ICT itself, demonstrated transformational use of ICT [9]. The use of the electronic whiteboard and laptop computers seemed to contribute to maintaining student motivation and interest [16] [18], which were also reiterated by the teacher in her post-observation interview.

Differences in the self-reported competence and confidence between the teacher and the student did not show student dominance, as previous research had suggested [10]. The level of self-reported confidence and competence in using the specified ICT indicated by the teacher and observed in the lesson reflects the belief that teachers need to be able to both use and effectively employ ICT [6]. Additionally, the interest and ability displayed by the teacher and the students in using ICT reflects what is becoming an essential skill [20], as well as the motivational and engagement aspects of ICT [16] [18]. This has the potential to expand with the subsequent introduction of a plethora of hand-held devices that have exploded into the ICT environment (for example, iPads) since the research was conducted.

The small number of participants in this study reduces the generalisability of the results to the general population. However, the use of a case study design enabled the context and situation to be explored [14], which was vital to the aim of the research. The phenomenon under investigation was bounded by the physical and social aspects of the classroom, which created the case in which the study was conducted [13]. Additionally, the multidimensionality of this phenomenon was based within a reality [14], and the reality of this case shares similarities with other Grade 6 classrooms in other schools.

\section{Acknowledgements}

The researcher wishes to thank the teacher, students, and other staff who assisted in the research discussed in this paper, as well as the doctoral supervisor, Professor Vaille Dawson. 


\section{References}

[1] T. Levin and R. Wadmany, “Teachers' views on factors affecting effective integration of information technology in the classroom: developmental scenery", Journal of Technology and Teacher Education, 16(2), Society for Information Technology \& Teacher Education, Chesapeake, VA, 2008, pp. 233-263. (Access date: 22 September 2008).

[2] A. Pina, and B. Harris, "Increasing teachers' confidence in using computers for education", Paper presented at the Annual Meeting of the Arizona Educational Research Organisation, Tucson, Arizona, November 1993. (Access date: 21 September 2008).

[3] J. E. Hinostroza, C. Labbe, M. Brun, M., and C. Matamala, "Teaching and learning activities in Chilean classrooms: Is ICT making a difference?”, Computers \& Education, 57, Elsevier, Amsterdam, 2011, Pp. 1358-1367. (Access date: 17 March 2011).

[4] Beardon, T., and J. Way, "ICT as a tool for learning - where are we going?” In J. Way \& T. Beardon (Eds.), ICT and Primary Mathematics (pp. 153-162), Open University Press, Maidenhead, UK 2003.

[5] P. Moore-Hart, Creating Learning Environments That Invite All Students To Learn Through Multicultural Literature and Information Technology. Childhood Education, Winter, 81 (2), 2004/2005, pp. 87-94; http://www.eric.ed.gov (Access date: 6 April 2008).

[6] I. Nikolova, “Teacher development in ICT: Vision and implementation”, in H. Taylor \& P. Hogenbirk (Eds.), Information and Communication Technologies in Education - the School of the Future (pp. 159-176), Kluwer Academic Publishers, Boston, NY, 2001.

[7] M. Windschitl and K. Sahl, “Tracing teachers' use of technology in a laptop computer school: The interplay of teacher beliefs, social dynamics, and institutional culture”, American Educational Research Journal, 39(1), American Educational Research Association, Washington, DC, 2002, pp. 165-205. (Access date: 24 August 2008).

[8] E. Smeets, "Does ICT contribute to powerful learning environments in primary education?" Computers \& Education, 44, Elsevier, Amsterdam, 2005, pp. 343-355. (Access date: 17 March 2011).

[9] J. Hughes, “The role of teacher knowledge and learning experiences in forming technology-integrated pedagogy”, Journal of Technology and Teacher
Education, 13(2), Society for Information Technology \& Teacher Education, Chesapeake, VA, 2005, pp. 227-302. (Access date: 22 September 2008).

[10] S. Guha, “Are we all technically prepared? Teachers' perspectives on the causes of comfort or discomfort in using computers at elementary grade teaching”, Paper presented at the Annual Meeting of the National Association for the Education of Young Children, November 8-11, 2000 Atlanta, GA. (Access date: 21 September 2008).

[11] W. A. Fryer, Technology integration lessons from the TLA, 2003, retrieved from http://www.wtvi.com/teks/03_04_articles/tla_lessons.h tml. (Access date: 4 October 2008).

[12] Australian Curriculum, Assessment and Reporting Authority [ACARA] (n.d.). My School; http://www.myschool.edu.au/

[13] R. K. Yin, Case Study Research: Design and Methods ( $4^{\text {th }}$ ed.), Sage Publications, Thousand Oaks, Ca, 2009.

[14] S. B. Merriam, Qualitative Research: A guide to design and implementation. Jossey-Bass, San Francisco, CA, 2009.

[15] Y. Zhao, K., Pugh, S. Sheldon, and J. L. Byers, "Conditions for classroom technology innovations", Teachers College Record, 104(3), Teachers College, New York, NY, 2002, pp. 482-515. (Access date: 6 April 2008).

[16] D. Chen, J. Hsu, and D. Hung, "Learning theories and IT: The computer as a tool”, In M. D. Williams (Ed.), Integrating Technology into Teaching and Learning (pp. 185-201), Prentice Hall Pearson Education, Singapore, 2000.

[17] J. Way, E. Lilley, C. Ruster, S. Johnco, L. Mauric, and L. Ochs, "Symposium: Interactive whiteboards and pedagogy in primary classrooms”, In Proceedings of the Australian Association for Research in Education Conference, Canberra, 29 November-3 December, 2009. (Access date: 16 March 2011).

[18] A. M. T. Bosman, M. van Huygevoort, and L. Verhoeven "Spelling feedback in an ICT-learning environment: Issues of proficiency, training efficiency, and transfer", International Journal of Educational Research, 45, Elsevier, Amsterdam, 2006, pp. 341-361. (Access date: 17 March 2011). 
[19] R. Jamieson-Proctor and G. Finger, Act to improve ICT use for learning: A synthesis of studies of teacher confidence in using ICT in two Queensland schooling systems. Australian Educational Computing, 23(2), 2008, pp. 12-18; http://eprints.usq.edu.au/4888/2/Jamieson-

Proctor_Finger_2008_PV.pdf (16 March 2011).

[20] U. Bunz, C. Curry and W. Voon, "Perceived versus actual computer-email-web fluency", Computers in Human Behavior, 23, Elsevier, Amsterdam, 2006, pp. 2321-2344. 